We are grateful to Dr. M. Lowry and Dr. G. Kundu for their help with the project and to Miss J. Hallum and Mr. H. Mansfield for permission to study patients under their care. We would also like to thank Sister D. Nowicka and other members of the staff of Sorrento Maternity Hospital for their help.

\section{References}

Baum, D., Cooper, L., and Davies, P. A. (1968). Lancet, 1, 598. Bonner, J, Goldberg, A., and Smith, J. A (1969). Lancet, 1, 457. Bronsky, D., Kiamko, R. T., Moncada, R., and Rosenthal, I. M. (1968) Pediatrics, 42, 606 .

Davis, J. A., Harvey, D. R., and Yu, J. S. (1965). Archives of Diseasc in Childhood, 40, 286 .
Dunnigan, M. G., Paton, J. P. J., Haase, S., McNicol, G. W., Gardner, M. D., and Smith, C. M. (1962). Scottish Medical fournal, 7, 159. Fanconi, A., and Prader, A. (1967). Helvetica Paediatrica Acta, 22, 205. Fanconi, A., and Prader, A. (1967). Helvetica Paediatrica Acta, 22, 2

Neale, F. C., Clubb, J. S., Hotchkiss, D., and Prosen, S. (1965). Fournal of Clinical Pathology, 18, 359.

Oppé, T. E., and Redstone, D. (1968). Lancet, 1, 1045.

Schachter, D. (1959). Fournal of Laboratory and Clinical Medicine, 54, 763.

Scott, P., and Warner, M. (1968). Unpublished.

Southgate, D. A. T., et al. (1969). Lancet, 1, 478.

Watney, P. J. M., and Scott, P. (1970). Unpublished observations.

Widdowson, E. M., and McCance, R. A. (1960). Chemical Composition of Foods, London, H.M.S.O.

Widdowson, E. M., and Spray, C. M. (1951). Archives of Disease in Child-

hood, 26, 205 . Discase. Philadelphia, Lean and Febiger.

\title{
Effects of Oral Contraceptives on Human Plasma Vitamin-A Levels
}

\author{
ISABEL GAL, CHRISTINE PARKINSON, IAN CRAFT
}

British Medical fournal, 1971, 2, 436-438

\begin{abstract}
Summary
Vitamin-A levels have been determined in healthy nonpregnant women and in women taking synthetic steroids to suppress ovulation. A significant increase has been found in those receiving oral contraceptives. Further work is necessary to determine whether this may affect the fetus in patients who become pregnant shortly after discontinuing oral contraception.
\end{abstract}

\section{Introduction}

Oral contraception is one of the most effective methods of birth control, but after the widespread introduction of these synthetic steroids there have been numerous reports on side effects. These have largely been concerned with clinical manifestations and derangements in metabolic functions (Spellacy and Carlson, 1966; Briggs and Staniford, 1969; Laurell et al., 1968; Briggs et al., 1970; Streiff, 1970). Nevertheless, little attention has been given to the influence of these agents on possible alterations in reproductive environment.

One such prerequisite postulated for normal reproduction to occur is that optimum levels of vitamin $A$ be present. Alterations in vitamin $A$ in animals have been shown to be associated with changes in reproductive capacity and an increased incidence of congenital malformations (Giroud, 1955). Relatively little is known about the influence of variations in vitamin-A levels on human reproduction, but initial studies have suggested an association between alterations in maternal vitamin-A levels and congenital defects (Gal et al., 1971). Steroid administration may be associated with abnormal fetal development, for an

\footnotetext{
Institute of Obstetrics and Gynaecology, Queen Charlotte's Hospital, London W.6

ISABEL GAL, M.D., Clinical Lecturer

CHRISTINE PARKINSON, L.I.BIOL., Senior Research Technician

Westminster Hospital, London S.W.1

IAN CRAFT, F.R.C.S., M.R.C.o.G., Senior Registrar
}

increased incidence of chromosome abnormalities in spontaneous abortions has been reported in women who have received oral contraceptives (Carr, 1967; Dhadial et al., 1970).

Steroid administration alters the circulating vitamin-A levels. Woollam and Millen (1960) reported that the teratogenic activity of vitamin $A$ in rats is accentuated by cortisone. These facts prompted an investigation into whether oral contraceptives have any significant influence on human vitamin-A status.

\section{Subjects and Methods}

Twenty healthy young volunteer women aged 20 to 32 years, with regular menstrual cycles, acted as controls for 22 women of the same age range who had been receiving oral contraceptive tablets for at least three months. The contraceptive tablets used included Gynovlar $(0.05 \mathrm{mg}$ ethinyloestradiol and $3 \mathrm{mg}$ norethisterone acetate); Minovlar ( $0.05 \mathrm{mg}$ ethyinloestradiol and $1 \mathrm{mg}$ norethisterone acetate); Norinyl-1 (0.05 mg mestranol and $1 \mathrm{mg}$ norethisterone); Lyndiol 2.5 (0.075 $\mathrm{mg}$ mestranol and $2.5 \mathrm{mg}$. lynestrenol); Minilyn (0.05 $\mathrm{mg}$ ethinyloestradiol and $2.5 \mathrm{mg}$ lynestrenol); Ortho-novin $(0.1 \mathrm{mg}$ mestranol and $2 \mathrm{mg}$ norethisterone); Ovulen $(0.1 \mathrm{mg}$ mestranol and $1 \mathrm{mg}$ ethynodiol diacetate); and Volidan $(0.05 \mathrm{mg}$ ethinyloestradiol and $4 \mathrm{mg}$ megestrol acetate).

To assess the influence of hormone levels on vitamin- $A$ metabolism both groups were studied on two occasions during one menstrual cycle-that is, during days 3 to 5 and during days 18 to 21 , when endogenous and exogenous hormone levels are respectively first low and then high. In the contraceptive group the first sample was therefore taken in the tablet-free interval.

Blood samples were taken after an overnight fast, at the same time each morning, into syringes covered in aluminium foil because of the light sensitivity of vitamin $A$. The samples were then centrifuged in foil-covered containers and the plasma was separated in a dark room and stored at $-20^{\circ} \mathrm{C}$. Vitamin-A and carotenoid levels were assayed by the Yudkin (1941) modification of the Kimble (1939) method.

To establish whether synthetic steroids interfere with these analyses, norethisterone acetate and ethinyloestradiol were added to plasma in concentrations equivalent to the highest levels found in the plasma of those receiving these particular preparations. The vitamin $\mathrm{A}$ was then assayed and the result 
compared with untreated plasma. As vitamin A also plays a part in the conversion of cholesterol to corticosteroids (Rogers, 1969), a similar checking experiment was undertaken with cholesterol. None of these substances showed interference with the vitamin-A and carotenoid readings with our standard estimation procedure.

\section{Results}

Variations in plasma vitamin A and carotenoids during the menstrual cycle in the two groups are shown in the Table. The

Variation of Plasma Vitamin-A and Carotcnoid Levels in Healthy Untrcatcd Women and in Those Receiving Oral Contraceptives

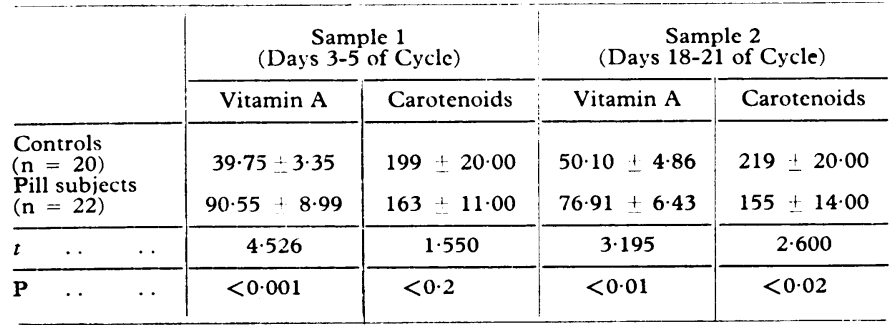

Vitamin-A and carotenoid levels expressed as $\mu \mathrm{g} / 100 \mathrm{ml}$ of plasma.

mean values and standard errors of the mean are shown together with a comparison of the two groups. All the results are shown in Figs. 1 and 2. Vitamin-A levels were significantly

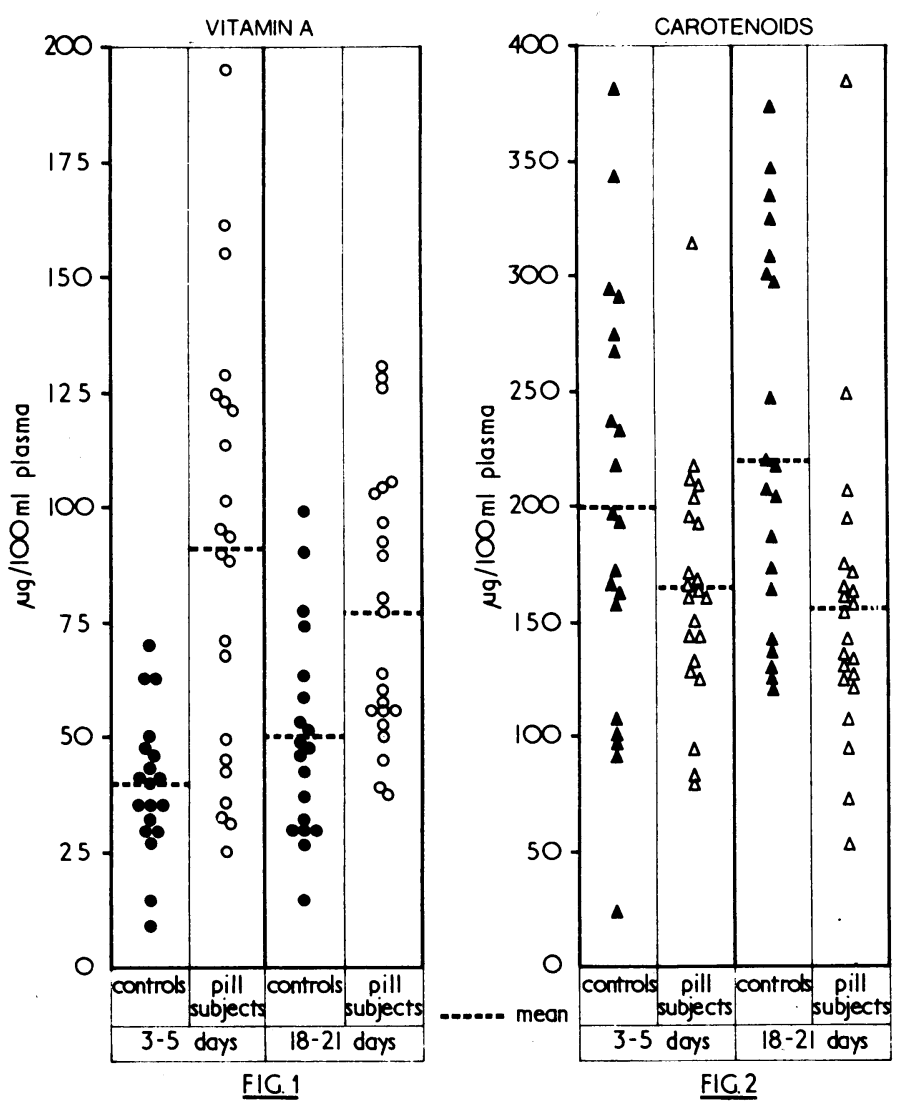

FIG. 1-Individual distribution of plasma vitamin-A levels. FIG. 2-Individual distribution of carotenoid levels.

higher in the oral contraceptive group on days 3 to 5 ( $P<0.001$ ) and days 18 to $21(P<0.01)$. The raised level in the first sample is of interest because this occurs during the tablet-free interval between courses of contraceptive pills, when most of the synthetic hormones have been excreted.

Variations in the plasma vitamin-A and carotenoid levels during the menstrual cycle in each group were calculated by the significance of difference between paired values from individual subjects, using the paired $t$ test. In the control group significant increases in vitamin-A levels $(P<0.02)$ were found at that time in the cycle, following ovulation (days 18 to 21 ), when physiological levels of sex hormones are high. There was no significant change in vitamin-A levels during the cycle in the oral contraceptive group $(P<0 \cdot 2)$. Carotenoid levels did not show significant changes during the cycle in the two groups, but those taking contraceptive tablets had a significantly lower value than the controls $(P<0.02)$ during days 18 to 21 .

\section{Discussion}

Vitamin-A and carotenoid status varies widely in different individuals and is influenced by many factors such as nutrition, age, health, etc. It is thought that the people participating in this study represent a fairly uniform population, since they were healthy nurses having similar nutritional standards.

Carotenoid levels are generally accepted as reflecting recent dietary intake, and it is interesting that the mean values showed no significant variation during the cycle in either group. However, the significant fall in the oral contraceptive group in the second half of the cycle when compared with controls suggests that plasma carotenoid levels are influenced by factors other than nutrition. In addition, the significant increase in circulating vitamin $\mathrm{A}$ in those taking contraceptive pills suggests that exogenous steroids have a profound influence on vitamin-A metabolism.

Endogenous sex hormones probably influence the distribution of vitamin $\mathrm{A}$ in the body, for men have a higher plasma concentration than women, whereas the latter have higher levels in the liver and other tissues (Moore, 1957). Circulating carotenoids are lower in women. The significant variation during the normal menstrual cycle reported here confirms that previously described (Laurence and Sobel, 1953) and suggests that the physiological levels of sex hormones influence vitaminA metabolism. Other substances show significant variations during the menstrual cycle, including plasma amino-acids (Craft and Wise, 1969).

Other information confirms our impression that exogenous steroids influence vitamin A. Oestrogens given to rats increases the tissue storage (György et al., 1947), and progestogens have a reverse effect (Grangaud et al., 1969). Similarly, stilboestrol given to women to suppress lactation reduces circulating vitamin A (Gal et al., 1971). It is not known what quantitative changes occur in the distribution of vitamin $A$ between the circulation and the tissues in those taking oral contraceptives of differing constitution. Goodman (1969) suggested that vitamin A is transported in plasma, bound to a specific $\alpha$-globulin, and this fraction of plasma protein has been reported to increase following oral contraceptive therapy (Laurell et al., 1968). This may in part explain some of the increase in circulating vitamin-A levels. However, this suggestion needs further clarification.

As regards the significance of the increased vitamin-A levels, it is important to note that none of the pill subjects had values approaching toxic levels $(300 \mu \mathrm{g} / 100 \mathrm{ml})$. Their mean vitamin-A value was $83 \mu \mathrm{g} / 100 \mathrm{ml}$ against $45 \mu \mathrm{g} / 100 \mathrm{ml}$ of plasma in the controls. However, we are concerned that even moderate hypervitaminosis A may have an unfavourable influence on reproduction in certain susceptible individuals in the event of conception occurring soon after discontinuing oral contraceptives. Part of the cause of this concern is the knowledge that both exogenous steroids and vitamin-A administration can induce congenital malformations in animals. In the field of human teratology, in addition to the association between recent hormone therapy and chromosome aberrations in spontaneous abortions (Carr, 1967; Dhadial et al., 1970), there is evidence that hormone tablets given in early pregnancy may be associated with congenital abnormalities (Gal et al., 1967). A study of women who have borne children with defects of the central nervous system has shown that they have significantly higher 
postpartum levels of plasma vitamin A than women who have borne normal children (Gal et al., 1971). The mode of teratogenic action of synthetic steroids and vitamin $A$ is as yet unknown, but the findings reported here suggest that further research should be undertaken into their effect on the reproductive environment.

This work has been supported by the Medical Research Council. We thank the volunteers who participated in this study, and Schering Chemicals Ltd. for providing synthetic steroids.

\section{References}

Briggs, M., Austin, G., and Staniford, M. (1970). Nature, 225, 81. Briggs, M., and Staniford, M. (1969). Lancet, 2, 742 Briggs, M., and Staniford, M. (1969).
Carr, D. H. (1967). Lancet, 2, 830.
Craft, I., and Wise, I. J. (1969). I.ancet, 2, 1138

Dhadial, R. K., Machin, A. M., and Thait, S. M. (1970). Lancet, 2, 20.

Gal, I., Kirman, B., and Stern, J. (1967). Nature, 216, 83.

Gal, I., Sharman, M. I., and Pryse-Davies, J. (1971). Advances in Tcratology, 5. In press

Giroud, A. (1955). Biological Medicine, 5, 44

Goodman, D. S. (1969). American fournal of Clinical Nutrition, 22, 911.

Grangaud, R., Nicol, M., and Desplanques, D. (1969). American fournal of Clinical Nutrition, 22, 991

György, P., Rose, G. F., and Shipiel, R. A. (1947). Archives of Biochemistry, $12,125$.

Kimble, Marion S. (1939). Fournal of Laboratory and Clinical Medicine, 24, 1055.

Laurell, C. B., Kullander, S., and Thorcll, J. (1968). Scandinavian fournal of Clinical and Laboratory Investigation, 21, 337.

Laurence, P. A., and Sobel, A. F. (1953). Journal of Clinical Endocrinology and Metabolism, 13, 1192.

Moore, T. (1957). Vitamin A, Chapt. 36. Amsterdam, Elsevier.

Rogers, W. E. (1969). American fournal of Clinical Nutrition, 22, 1003.

Spellacy, W. N., and Carlson, K. L. (1966). American fournal of Obstetrics and Gynecology, 95,474

Streiff, R. R. (1970). Fournal of the American Medical Association, 214, 105. Woollam, D. H. M., and Millen, J. W. (1960). In Ciba Foundation Sympo

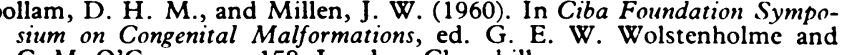
C. M. O'Connor, p. 158. London, Churchill.

Yudkin, S. (1941). Biochemical fournal, 35, 551.

\title{
Action of Thymoxamine on Mydriasis induced by Levodopa and Dopamine
}

\author{
A. S. D. SPIERS, \\ D. B. CALNE, \\ S. D. VAKIL, \\ T. M. FRENCH
}

British Medical fournal, 1971, 2, 438-439

\begin{abstract}
Summary
Eye-drops of levodopa and dopamine induce pupillary dilatation which is inhibited by thymoxamine, an alpha-adrenergic blocking drug. This indicates that the mydriatic action of levodopa and dopamine involves excitation of alpha-adrenergic receptors of the dilator pupillae muscle. Such a conclusion is in accord with the previously expressed suggestion that levodopa is rapidly converted to dopamine, which displaces noradrenaline from adrenergic nerve endings.

The findings that dopamine exerts alpha-adrenergic effects at the periphery may be construed as evidence in support of the view that the hypotensive action of levodopa is mediated via the central nervous system.
\end{abstract}

\section{Introduction}

Levodopa has now been established as the most powerful drug available for the treatment of a considerable proportion of Parkinsonian patients. In some cases, however, the therapeutic action of levodopa is accompanied by adverse effects which include alterations in autonomic function. The most significant of these effects is hypotension, more pronounced in the erect posture, and rarely severe enough to limit

Royal Postgraduate Medical School, London W12 0HS

A. S. D. SPIERS, PH.D., M.R.A.C.P., Research Physician, Leukaemia Unit D. B. CALNE, D.M., M.R.C.P., Lecturer in Neurology, Department of Medicine (Neurology)

S. D. VAKIL, M.R.C.P., Senior Registrar, Department of Medicinc (Neurology)

University College Hospital, London WC1E 6JJ

T. M. FRENCH, M.sC., B.PHARM., Deputy Chief Pharmacist levodopa therapy (Yahr, Duvoisin, Schear, Barrett and Hochn, 1969; Calne, Brennan, Spiers, and Stcrn, 1970; McDowell, 1970). In an attempt to analyse some of these actions on the sympathetic nervous system the response of the dilator pupillae muscle to levodopa and dopamine eye-drops has been investigated. In these studies both drugs have been found to induce pupillary dilatation (Spiers and Calne, 1969; Calne and Spiers, 1970; Weintraub, Gaasterland, and Van Woert, 1970). It has been suggested that this mydriasis is achieved by the release of noradrenaline from adrenergic nerve endings in the iris. In order to investigate this possibility the effect of thymoxamine (an alpha-adrenergic blocking drug) on the mydriatic action of levodopa and dopamine has been studied.

\section{Subjects and Methods}

Subjects.-Twenty-four normal volunteer subjects took part in these investigations-eight were treated with levodopa alone, eight with dopamine alone, four with levodopa and thymoxamine, and four with dopamine and thymoxamine.

Design.-Eye-drops of levodopa or dopamine were instilled into the conjunctival sac of one eye at hourly intervals for six hours. Thymoxamine was given one-and-a-half hours and half-an-hour before administration of levodopa or dopamine. Further doses of thymoxamine were given at hourly intervals two to six hours after starting levodopa or dopamine if the treated eye displayed any mydriasis. All drug administration consisted of two drops. The pupillary diameter was recorded in both eyes by an observer who did not know which eye was being treated. Measurements were made to the nearest $0.5 \mathrm{~mm}$ in artificial light, using the pupillometer of a standard ophthalmoscope.

Drugs.-Levodopa, $1{ }^{\circ}{ }_{0}$ aqueous solution, was buffered with borate to $\mathrm{pH} 7$. Dopamine hydrochloride, $10^{\prime \prime}$ "aqueous solution, was buffered to $\mathrm{pH} 6.5$ with bicarbonate sulphite. Thymoxamine hydrochloride, $0 \cdot 1^{\circ} \mathrm{j}$ aqueous solution, was buffered to $\mathrm{pH} 7$ with borate. 